\title{
Evaluation of Controlled Release Theophylline Microspheres Prepared with Cellulose Acetate Using Solvent Evaporation Method
}

\section{Sunit K Sahoo ${ }^{1 *}$, Satyabrata Barik ${ }^{1}$, Gourhari Dehury ${ }^{1}$, Subhakanta Dhala', Subhakanta Kanungo', Bhakti B Barik ${ }^{2}$ and Kishore K Puhan ${ }^{3}$}

${ }^{1}$ University Department of Pharmaceutical Sciences, Utkal University, Vani-Vihar, Bhubaneswar, Orissa. Pin751004, ${ }^{2}$ College of Pharmacy, Jazan University, P.O. Box 114, Jazan, 45142, Kingdom of Saudi Arabia , ${ }^{3}$ Glenmark Research Center, Nasik, India.

\begin{abstract}
Purpose: To formulate theophylline microspheres with cellulose acetate using solvent evaporation method and evaluate the effect of various processing factors on their characteristics.

Methods: Microspheres containing theophylline were prepared with a hydrophilic, biocompatible polymer - cellulose acetate - by an emulsion solvent evaporation technique using an acetone/liquid paraffin system containing Span 80 as a surfactant. The effect of processing factors, e.g., varying drug/polymer ratio $(1: 1,1: 2,1: 3)$ and temperature $\left(10\right.$ and $\left.35{ }^{\circ} \mathrm{C}\right)$ on microsphere characteristics and drug release were examined. Similarly, microspheres with a drug/polymer ratio of 1:3 incorporating Span 20 were also also prepared and evaluated.

Results: The microspheres were white, free-flowing and spherical. The yield varied from 73.0 to $87.5 \%$ while entrapment efficiency was in the region of 71.8 to $92.4 \%$. High drug/polymer ratio, Span 80 (surfactant) and processing temperature between 10 and $30{ }^{\circ} \mathrm{C}$ produced formulations with better drug entrapment efficiency. High drug/polymer ratio, low processing temperature and low HLB value of surfactant enhanced the sustained drug release characteristics of the microspheres.

Conclusion: The combination of three suitable factors - Span mixture (with HLB value of 4.3), processing temperature of $10^{\circ} \mathrm{C}$ and drug/polymer ratio of 1:3 - produced a suitable controlled release theophilline microsphere formulation which could be effective for the management of asthma.
\end{abstract}

Keywords: Microsphere, Emulsion solvent evaporation, Theophylline, Temperature, HLB value. 


\section{INTRODUCTION}

The microencapsulation technique by solvent evaporation process has been extensively studied in recent years for the preparation of microspheres. This is a complex process and requires strict control of several processing parameters such as rate of solvent evaporation, stirring rate, viscosity of polymeric phase, drug polymer ratio, volume ratio between inner phase and outer phase and amount of surfactant, in order to develop a therapeutically effective dosage form [1].

Some studies have been carried out earlier using polymethacrylate polymers (Eudragit RS 100, RSPO, etc) and dextran regarding the effect of processing temperature on microsphere characteristics $[1,2]$ but no work has been reported, to the best of our knowledge, on the effect of processing temperature and Span HLB value on cellulose acetate microsphere formulation and release characteristics. The role of temperature in emulsion solvent evaporation process is a matter of great significance since it affects the rate and way at which the organic solvent is removed from the microspheres and ultimately, the shape, size, and drug loading efficiency [1].

Surface active agents play a significant role in microsphere formulation by emulsification solvent evaporation method. They have the properties of adsorbing to the interface and stabilizing the emulsion droplets by preventing their aggregation. Cellulose acetate (CA) the acetate ester of cellulose is a biocompatible hydrophilic polymer and has been used as a microencapsulating agent in several studies [2- 4]. Theophylline (TH), the drug of choice for the treatment of asthma has a short elimination half-life, and its toxicity is dose-dependent. All the side effects can be controlled efficiently if the drug is administered as a controlled release formulation [5].

To the best of our knowledge, the effect of process parameters such as temperature and hydrophilic/lipophilic balance (HLB) value of surfactant on characteristics of theophylline (TH) microspheres prepared with cellulose acetate (CA) has not been carried out. Therefore, the objective of this study was to evaluate the effect of drug/polymer ratio, process temperature and surfactant HLB value on the shape, size, flow property, drugloading efficiency and drug release characteristics of theophylline CA microspheres prepared by solvent evaporation method using acetone/liquid paraffin system, as well as determine the potentially most suitable controlled release formulation for asthma management

\section{EXPERIMENTAL}

\section{Materials}

Theophylline (TH) and cellulose acetate (CA) were obtained as gifts from Macleod, Mumbai, India, while Span 20 and 80 were procured from Central Drug House (P) Ltd, New Delhi, India. All other reagents and solvents used were of pharmaceutical or analytical grade.

\section{Method of preparation}

Cellulose acetate (CA), ranging from 0.25 to $0.75 \mathrm{~g}$, was dissolved in $10 \mathrm{ml}$ of acetone and $0.25 \mathrm{~g}$ of theophylline (the fraction passing through a sieve with aperture size of $36 \mu \mathrm{m}$ ) was suspended in the CA solution and stirred with a magnetic stirrer. The resultant dispersion was poured into $100 \mathrm{ml}$ of light liquid paraffin, containing $1.5 \% \mathrm{w} / \mathrm{v}$ of Span 80 (HLB value 4.3) as an emulsifying agent, in a $250 \mathrm{ml}$ beaker which was rotated in a water bath at $600 \mathrm{rpm}$ at $30{ }^{\circ} \mathrm{C}$ for $7 \mathrm{~h}$. The resulting microspheres were filtered through a Whatman filter paper no. 1. The residue was washed 4 - 5 times in $50 \mathrm{ml} \mathrm{n}$-hexane on each occasion. The microspheres were dried at room temperature for $24 \mathrm{~h} \quad[6,7]$. Microspheres with varying drug/polymer ratio $(1: 1,1: 2,1: 3)$ were coded F1, F2 and F3, respectively. Microspheres were also prepared with a drug/polymer ratio of $1: 3$ 
using Span 80 (HLB value, 4.3) at 10 and 35 ${ }^{\circ} \mathrm{C}$ and denoted $\mathrm{F} 4$ and $\mathrm{F} 5$, respectively. Similarly, microspheres with a drug/polymer ratio of $1: 3$ using Span 20 (HLB value, 8.6) at a temperature of $30^{\circ} \mathrm{C}$ was denoted $\mathrm{F} 6$.

\section{Determination of microsphere yield}

The microspheres were weighed and the yield of microspheres was calculated using Eq 1.

Yield $(\%)=(A / B) \times 100$

where $A$ is the weight of microspheres obtained and $B$ is the theoretically expected weight of microspheres.

\section{Assessment of size distribution of microspheres}

The microspheres were separated into different size fractions by sieving for $10 \mathrm{~min}$ using a mechanical sieve shaker (Cuprit Electrical Co., India) containing standard sieves with apertures of $710,500,355,250$ and $180 \mu \mathrm{m}$, respectively. The particle size distribution of each of the microsphere batch was determined [7] and their mean particle size calculated using Eq 2.

Mean particle size $=\Sigma(\mathrm{P} \times \mathrm{W}) / \Sigma \mathrm{W}$

where $P$ is the mean particle size of the fraction and $\mathrm{W}$ is the weight of the fraction.

\section{Micromeritic studies}

The flow properties of the microspheres were evaluated by determining Carr's index [7] as in Eq 3.

Carr's index $=\{(T D-B D) \times 100\} / T D$

where TD is tapped density and BD bulk density. The bulk and tapped densities were measured in a $10 \mathrm{ml}$ graduated measuring cylinder.

\section{Surface accumulation studies}

This study was conducted to estimate the amount of drug present on the surface of the microspheres. An accurately weighed quantity of the microspheres $(50 \mathrm{mg})$ was suspended in $50 \mathrm{ml}$ of phosphate buffer $(\mathrm{pH}$ 6.8) and agitated on a mechanical shaker for $15 \mathrm{~min}$. The amount of drug leached from the surface of the microspheres was analyzed spectrophotometrically using Systronic 2101 UV-Visible spectrophotometer at $271 \mathrm{~nm}$ and expressed as a proportion of the entrapped drug in the microspheres [9].

\section{Drug entrapment efficiency}

About $50 \mathrm{mg}$ of accurately weighed microspheres were added to $50 \mathrm{ml}$ of phosphate buffer, (pH 6.8) and then agitated on a mechanical shaker for $24 \mathrm{~h}$. The mixture was filtered with Whatman membrane filter, BA85 grade ( $0.45 \mu \mathrm{m}$ pore size) and, after suitable dilution, analyzed spectrophotometrically at $271 \mathrm{~nm}$ using Systronic 2101 UV - Visible spectrophotometer.

\section{Scanning electron microscopy (SEM)}

A scanning electron microscope (JEOL JSM - 5200) was used to characterize the surface topography of the microspheres at $20 \mathrm{kV}$. Prior to examination the microspheres were fixed on a metallic support with a thin adhesive tape and microspheres were coated with gold under vacuum (fine coat, ion sputter JFC - 1110) to render them electron conductive.

\section{In vitro release studies}

In vitro release studies on the microspheres (355 $\mu \mathrm{m}$ fraction) were carried out at $37^{\circ} \mathrm{C}$ in $500 \mathrm{ml} 0.1 \mathrm{M} \mathrm{HCl}(\mathrm{pH} \mathrm{1.2})$ for the first $2 \mathrm{~h}$ and then in $500 \mathrm{ml}$ phosphate buffer $(\mathrm{pH} \mathrm{6.8)}$ in a USP basket type dissolution test apparatus (Labindia, Disso-2000, Mumbai, India) rotated at $100 \mathrm{rpm}$. At preset time intervals, 2 $\mathrm{ml}$ aliquots were withdrawn and replaced by an equal volume of fresh dissolution medium. The withdrawn samples were filtered $(0.45$ $\mu \mathrm{m}$ pore size) and, after suitable dilution, analyzed spectophotometrically at $271 \mathrm{~nm}$. Each test was carried out in triplicate. 
Table 1: Some of the characteristics of the microspheres $( \pm S D, n=3)$

\begin{tabular}{cccccc}
\hline $\begin{array}{c}\text { Batch } \\
\text { code }\end{array}$ & Yield (\%) & $\begin{array}{c}\text { Carr's } \\
\text { index }\end{array}$ & $\begin{array}{c}\text { Mean particle size } \\
(\boldsymbol{\mu m})\end{array}$ & $\begin{array}{c}\text { Surface } \\
\text { drug }(\%)\end{array}$ & $\begin{array}{c}\text { Encapsulation } \\
\text { efficiency \% }\end{array}$ \\
\hline${ }^{*} \mathrm{~F} 1$ & $85.3 \pm 4.7$ & 8.81 & $463 \pm 2.6$ & $3.6 \pm 0.0 .2$ & $78.6 \pm 1.3$ \\
${ }^{*} \mathrm{~F} 2$ & $85.4 \pm 2.6$ & 7.38 & $521 \pm 4.4$ & $2.1 \pm 0.3$ & $86.2 \pm 2.0$ \\
${ }^{*} \mathrm{~F} 3$ & $78.5 \pm 1.5$ & 4.94 & $608 \pm 2.0$ & $1.2 \pm 0.1$ & $90.9 \pm 1.8$ \\
${ }^{*} \mathrm{~F} 4$ & $85.2 \pm 2.2$ & 5.22 & $386 \pm 3.6$ & $1.4 \pm 0.2$ & $93.4 \pm 0.9$ \\
${ }^{* * *} \mathrm{~F} 5$ & $87.5 \pm 1.0$ & 9.90 & $731 \pm 2.0$ & $4.0 \pm 0.3$ & $71.8 \pm 1.2$ \\
${ }^{\mathrm{a}} \mathrm{F} 6$ & $72.9 \pm 2.6$ & 5.38 & $747 \pm 0.6$ & $12.0 \pm 0.5$ & $79.1 \pm 2.4$ \\
\hline
\end{tabular}

${ }^{*}$ Formulations containing drug/polymer ratio of 1:1, 1:2, 1:3 incorporating Span 80 and prepared at $30{ }^{\circ} \mathrm{C}$, are denoted F1, F2 and F3, respectively; F4 contain drug/polymer ratio 1:3, Span 80 and prepared at $10{ }^{\circ} \mathrm{C}$; F5 and F6 contains drug/polymer ratio $1: 3$, Span 80 , and prepared at 35 and $30^{\circ} \mathrm{C}$, respectively

\section{Statistical analysis}

The quantitative data were expressed as mean \pm standard deviation (SD), and statistical analysist on the data were performed using one-way ANOVA (Graph Pad Prism 5). Differences between formulations were considered to be significant at $p \leq 0.05$.

\section{RESULTS}

\section{Characteristics of microspheres}

The microspheres were white, free-flowing and spherical. The yield varied from $72-85$ $\%$. The quantitative characteristics of the microspheres are shown in Table 1. Carr's index, which is a measure of flow property, was $<10$ for all the formulations suggesting that they possessed excellent flow properties [10]. Higher polymer/drug ratio, processing temperature and surfactant HLB value of Span lead to increase in the mean particle size of microspheres. The entrapment efficiency of the various microspheres was in the range 70.8 to $92.4 \%$. Formulation F3 had higher drug loading than F6 $(p \leq 0.05)$. Higher polymer/drug ratio, Span 80 and processing temperature of 10 and $30{ }^{\circ} \mathrm{C}$ favoured higher drug entrapment.

\section{Scanning electron microscopy (SEM)}

The SEMs of the microspheres are displayed in Fig 1 with Fig $1 \mathrm{~A}(\mathrm{~F} 4)$ showing the general appearance of the microspheres. F3 (Fig 1B) had a smooth surface without visible evidence of drug particles on its surface while F6 (Fig 1C) shows the presence of drug particles on the microsphere surface. Fig 1D (SEM of F5) indicate some holes and fractures on the surface.

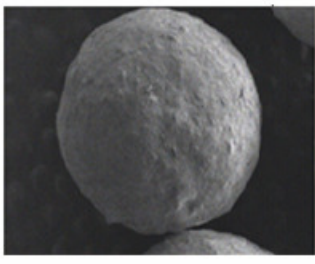

(A)

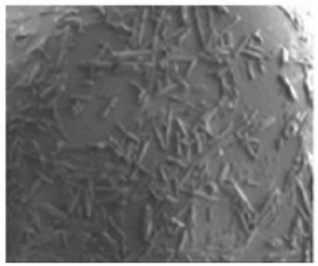

(C)

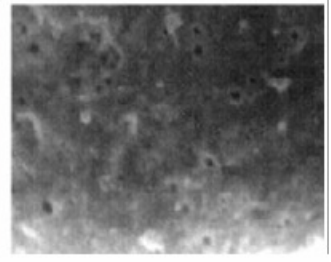

(B)

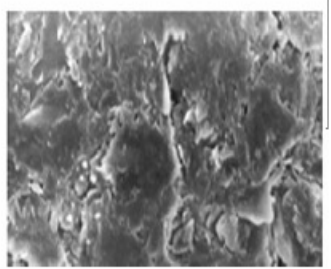

(D)
Fig 1: SEM photomicrographs of some microsphere formulations: $(A)=F 4(X 50) ;(B)=F 3(X 200) ;(C)=F 6(X$ $50)$, and shows the presence of drug particles on microsphere surface; and (D) = F5 (X 200), and shows holes and fractures on microsphere surface

\section{In vitro drug release}

Higher polymer/drug ratio, lower processing temperature and low HLB value of Span had an elevated effect on the sustained release characteristics of the microspheres. 


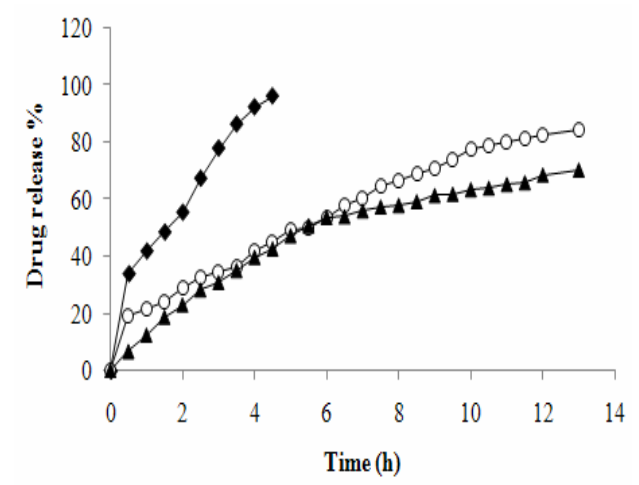

Fig 2: Effect of drug/polymer ratio on drug release from

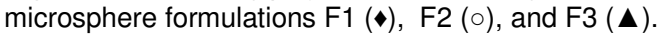

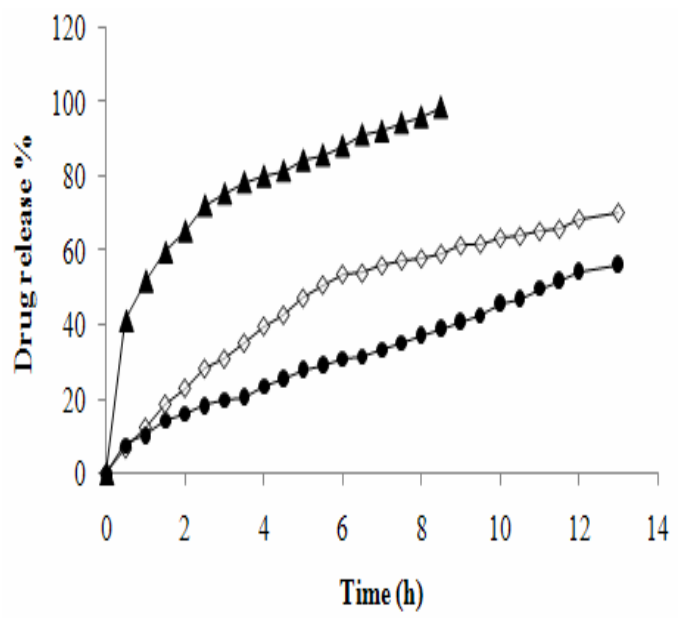

Fig 3: Effect of processing temperature on drug release

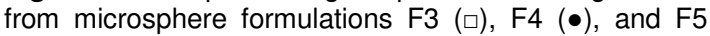
$(\Delta)$

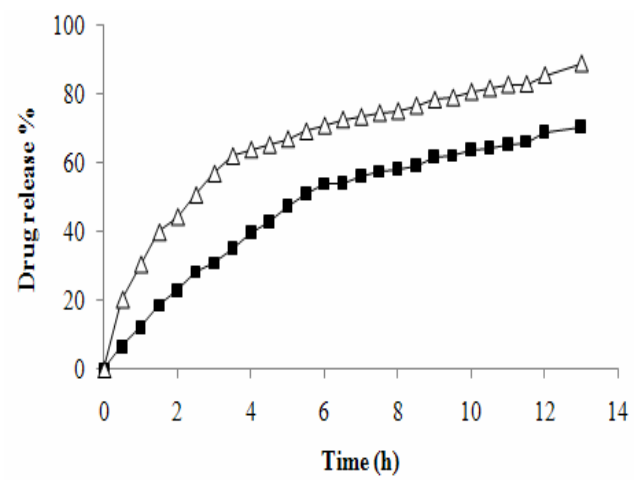

Fig 4: Effect of HLB value of Span on drug release from microsphere formulations F3 $(\square)$ F3 and F6 $(\Delta)$.

\section{DISCUSSION}

\section{Microsphere size}

The increase in particle size of the microspheres with increase in polymer/drug ratio was due to the fact that the viscosity of the dispersed phase increased with increase in polymer/drug ratio, resulting in larger emulsion droplets which were difficult to break and, precipitated to become the microspheres [10]. Increase in temperature from 10 to $35{ }^{\circ} \mathrm{C}$ favoured formation of larger microspheres and this may be explained by the likelihood that at the lower temperature, when the polymeric phase was added to the oil phase and stirred, extensive emulsification of the polymeric phase occurred with the solvent in the polymeric phase diffusing into the outer oil phase, and evaporating from the system, and thus resulting in small-size microparticles, However, the higher temperature increased the rate of solvent evaporation with the emulsion droplets hardening faster and the stirrer shear force unable to break the droplets, thus leading to formation of larger particles $[1,6]$.

The surfactant type used also affected particle size as Span 80 (HLB value, 4.3) resulted in the formation of comparatively smaller particle than Span 20 (HLB value, 8.6). This may be due to better stabilization of the emulsified droplets at the lower HLB value as Span 20 may have facilitated collision of small emulsified droplets to form larger particles.

\section{Drug entrapment}

The increase in drug entrapment efficiency with increase in polymer/drug ratio may be attributed to increase in polymer viscosity with the result that the microsphere hinders escape of the entrapped drug. Formulations F3 and F4 showed > $90 \%$ entrapment efficiency, suggesting that process temperatures $\leq 30{ }^{\circ} \mathrm{C}$ had no effect on drug entrapment. However, at $35{ }^{\circ} \mathrm{C}$, increased solvent evaporation created holes and 
fractures in the microsphere (F5, Fig 1D). These flaws constituted channels for the escape of the entrapped drug into the processing medium, leading to low drug entrapment.

\section{Drug release}

As polymer/drug ratio increased, drug release became more sustained because the polymeric phase became more viscous and this, in turn, strongly shielded the drug and hampered the diffusion of the dissolution medium into microsphere core to dissolve the drug as well as the diffusion of the dissolved drug out of the microsphere [11-13]. Lower processing temperature reduced the rate of drug release from the microspheres.

The photomicrographs indicate that while the microspheres formulated at $10{ }^{\circ} \mathrm{C}$ had no holes on their surfaces, those formulated at 30 and $35{ }^{\circ} \mathrm{C}$ showed the presence of either holes or holes plus fractures on their surfaces. These flaws probably acted as channels for the dissolution medium to access the core of the microspheres as well as diffusion of the dissolved drug from the microspheres.

Formulation F6 released drug in a faster manner than F3 due probably to the higher HLB value of Span 80 which facilitated the formation of a more stable microsphere with a greater capacity to retard drug diffusion than the microspheres (F3) prepared with Span 20 as the emulsifying agent.

\section{CONCLUSION}

Formulation F4, which combined three optimized process factors, namely, Span 80 (HLB value, 4.3), processing temperature of $10^{\circ} \mathrm{C}$ and drug/polymer ratio $1: 3$, yielded the satisfactory sustained theophylline release formulation of all the formulations evaluated

\section{ACKNOWLEDGEMENT}

The authors acknowledge Macleod, Mumbai India, for kindly supplying the theophylline used in this work. The authors are also grateful to Regional Research Lab. Bhubaneswar, Orissa, India, for making available facilities for the characterization studies.

\section{REFERENCES}

1. Sahoo SK, Dhal S, Mohapatro PK, Behera BC, Barik BB. Effect of processing temperature on Eudragit RS PO microsphere characteristics in the solvent evaporation process. Pharmazie 2007; 62: 638-639.

2. Yasunori M, Yoshinori O, Shigeru Y, Kozo T. Effect of temperature-increase rate on drug release characteristics of dextran microspheres prepared by emulsion solvent evaporation process Int J Pharm 2006; 324: 144-151.

3. Soppimath KS, Kulkarni AR, Aminabhavi TM, Bhaskar C. Cellulose acetate microspheres prepared by $\mathrm{o} / \mathrm{w}$ emulsification and solvent evaporation method. J Microencapsul 2001; 18: 811-817.

4. Arida A, Bassam A, Jaghbir M, ElAlem M, Sabri R, AbuZeid $R$. Development of SustainedRelease Ibuprofen Microspheres Using Solvent Evaporation Technique. Archiv der Pharmazie 1999; 332 : 405-407

5. Ozer O, Bmutlu ST. Development and in vitro evaluation of topically applied cinnamic acid formulations. Pharmazie 2007; 62: 138-144.

6. Ronik TM, Frlan R, Bogataj M, Bukovec P, Mrhar A. Effect of preparation temperature in solvent evaporation process on eudragit $R S$ microsphere properties. Chem Pharm Bull 2005; 53: 143-146.

7. Chowdary KPR, Koteshwara RN, Malathi K. Ethyl cellulose microspheres of glipizide: Characterization, in vitro and in vivo evaluation. Indian J Pharm Sci 2004; 66: 412416.

8. Obeidat WM, Price JC. Evaluation of enteric matrix microspheres prepared by emulsion-solvent evaporation using scanning electron microscopy. J Microencapsulation 2004; 21, 47-57.

9. Ghosh A, Nath LK, Roy BK, Roy P. A study on the effect of different polymers on frusemideloaded calcium alginate micropellets prepared by ionotropic gelation technique. Indian $J$ Pharmaceut Educ Res 2007; 41: 329-336.

10. Sahoo SK, Mallick AA, Barik BB, Senapati PC. Preparation and in vitro evaluation of ethyl cellulose microspheres containing stavudine by the double emulsion method. Pharmazie 2007; 62: 117-121. 
11. Lee JH, Park TG, Choi HK. Effect of formulation and processing variables on the characteristics of microspheres for water soluble drugs prepared by $w / 0 / 0$ double emulsion solvent diffusion method. Int J Pharm 2000; 196: 7578.

12. Jones DS, Pearce KJ. Investigation of the effects of some process variables on, microencapsulation of propranolol $\mathrm{HCl}$ by solvent evaporation method. Int J Pharm 1995; 118: 199-205.

13. Obeidat WM, Price JC. Viscosity of polymer solution phase and other factors controlling the dissolution of theophylline microspheres prepared by the emulsion solvent evaporation method. J Microencapsul 2003; 20: 57-65. 